\title{
The rise of the 'silver surfer': Online social networking and social inclusion for older adults
}

\section{Christina Doyle}

Australian Department of Human Services

\section{Sophie Goldingay}

\section{Deakin University}

\begin{abstract}
As the proportion of older adults continues to grow in many Western countries, there are increasing concerns about how to meet their needs. Ensuring social connectedness and inclusion is one way to support older adults' wellbeing. Online social networking has become common place amongst younger age groups, suggesting its possible usefulness for older adults, in order to combat isolation and loneliness. Some quantitative studies have already explored the amount and degree of online social networking amongst older adults. To add further understanding of how older adults experience social inclusion via the internet, the current qualitative study aimed to explore older adults' subjective experience of online social networking. Findings demonstrated a number of supports and barriers to social inclusion which reflect barriers to social inclusion of older adults in the non-virtual world. Recommendations to support social inclusion of isolated older adults via online social networking are suggested.
\end{abstract}

Keywords: older adults, social networking, social inclusion, internet, social isolation, wellbeing 


\section{Introduction}

Over the last decade there has been much publicity about the ageing of the Australian population and what this may mean for older people and future generations (Healy, 2004). It is estimated that by the year 2056 one-quarter of Australians will be over the age of 65 years (Australian Bureau of Statistics [ABS], 2008). As the population ages, there is increasing recognition from policy makers of the social needs of those in their senior years (Australian Institute for Primary Care, 2008). It has been observed that older citizens can feel displaced in their own communities due to increasing younger newcomers with different lifestyles (Phillipson, 2007). In addition, restricted mobility and death of spouse, family and friends, and reduced financial means can lead to isolation and loneliness (McLennan, 1999). It has also been observed that that there is an agerelated digital divide (Maidment \& Macfarlane, 2009) with younger adults more likely to use the internet than their more senior counterparts (Fox as cited in Hogeboom et al., 2010). As Nevill (2009) eloquently observes, "[w]hat was the 'golden age' for many is now emerging as the era of the 'black dog"' (p.134).

The growth of social networking media via the internet has sparked interest in the potential for internet use to strengthen social networks amongst older adults (Blaschke, et al., 2009; Hogeboom et al., 2010; Hughes \& Heycox, 2010; Lam \& Lam, 2008; Nimrod, 2010). In a study of online communities for seniors Nimrod (2010) found that being part of an online community helped members to cope with stress, losses and negative events. Membership also had the potential to protect, restore and even transform members' self-perceptions. Over a one year research period there was a constant increase in the daily activity level of the online communities with discussion ranging from very private to public subjects (Nimrod 2010, p. 390). The most active threads were those that offered fun. A reason for this may be because they offer relief and distraction from stressful life circumstances. Much of the literature points to a positive association between the use of the internet, perceived well-being and lower life stress (Blaschke, Freddolino \& Mullen 2009; Campbell 2008; Hughes \& Heycox 2010; Lam \& Lam 2008; Mukherjee 2010; Nimrod 2010; Selwyn 2004; Westlake, Evangelista, Stromberg, Ter-Galstanyan, Vazirani, \& Dracup 2007). However, a search of the literature highlighted that little is known about the subjective meaning of the use of the 
internet for social networking amongst older adults (Buse, 2009; Selwyn, 2004), why and how some older adults choose to use it or not, the nature of internet usage and what supports they draw upon (Selwyn, 2004).

This paper discusses the findings of a qualitative study that explored older adults' experiences with the use of the internet and social media. The lived experience of the participants and the workings of the age-related digital divide are explored with particular reference to financial limitations, internalized restraints around age-related deservingness and value of their time, notions of what constitutes an upstanding or virtuous citizen, and how power relations serve to limit the benefits of online social networking for older adults. Strategies are proposed that support the social inclusion of older people.

\section{Method}

This is a qualitative study using a grounded theory approach and was exploratory in nature due to its sample size of five participants. Thus, the themes observed in the data need to be investigated in more depth by further research. The study employed a constructivist grounded theory approach to develop knowledge as the study progressed rather than force preconceived ideas onto the data (Charmaz, 2006). Interviewing during June 2011 elicited the views of the interviewee's subjective world, and the use of reflexivity supported data gathering (Mruck \& Mey, 2007). Eligibility to participate in this study was limited to people seventy years or older who use a computer and access the internet. This study was undertaken as an Honours project, conducted by the first author alongside course work; due to time pressures it was necessary to limit the scale of the study. Participants were selected through a sample of convenience, for pragmatic reasons, as the intention was to select an "information rich" sample in a short space of time (Marlow \& Boone, 2005, p. 144). As mentioned above, five people aged from 75 to 86 years participated in the study.

Participants were recruited from a regional community, located on the outskirts of Geelong, Victoria. All participants were white Australians and the language spoken at home was English. The inclusion of participants from culturally diverse backgrounds would have added greater depth to the study and this limitation should be addressed in 
future research. However, this lack of cultural diversity was not unexpected as less than eight percent of people living in this community are from a non-English speaking background (City of Greater Geelong, 2011). The sample included four females and one male. This gender ratio was not surprising as the advertising for the study was conducted through the Lara Community Centre and the observations of the researcher revealed that more women than men frequent the Community Centre. This gender bias of this study is also a limitation as the experience of ageing and social networking is likely to vary dependent on gender.

Four of the participants had experienced the loss of a spouse through divorce or death and one participant was living in a marital relationship. Living alone is a predictor of social isolation and loneliness it is also positively associated with depression (Nevill, 2009). Therefore, it should be noted the relationship status of participants is also likely to have influenced findings. Participants living arrangements varied, three were living in detached houses, one in a retirement village and one was residing in a granny flat on the property of a family member. These living arrangements were unsurprising as the vast majority of older adults live in private residences and the number of people living alone increases with age (ABS, 2006). Participants' years of experience using computers ranged from six to more than twenty years.

In order to protect anonymity in a small community of older adults, all names have been changed to pseudonyms that are non-gender specific and the names are allocated randomly to excerpts instead of being matched to particular participants throughout this paper Transcripts of interviews were made available to all five participants and each participant was invited to provide feedback, edit their interview and ask questions. Only one participant chose to receive a transcript of their interview and no changes were made. Ethics approval was received via the University low risk ethics process.

\section{Analysis}

All interview transcription was conducted by the first author allowing for greater engagement with the data and emergent themes. During the initial stage, the first author named each line of data with initial codes, known as line-by-line coding. This method was useful to separate the data into categories, it also helped define implicit 
meanings and promote analytical thinking in the research process. What seemed to be the most useful initial codes were selected and where possible codes based on the words or actions of participants (vivo codes) were used. A concept map was also developed and memos were written to support the ongoing analysis of themes (Charmaz, 2006). The memo writing and analysis involved repeatedly going back to the data to make comparisons and look for similarities and differences.

\section{Findings}

Seven themes were identified during the analysis. These are new identities, social connectedness, productive use and value of time, lack of support to maximise networking opportunities, negotiating power relationships, and what it means to 'make do'. Themes are discussed with particular reference to the use of Facebook, Skype and photo sharing.

\section{New identities beyond the stereotypes: The rise of the 'silver surfer'}

Participants varied in their level of computer skills from novice to 'silver surfer'. Much of the literature argues that older adults are open to learning new internet tools and perceive them as having positive benefits (Blaschke et al., 2009). The findings of the current study found this was indeed the case. All five participants expressed a desire to learn new ways of using the internet and also spoke about confidence in their ability to do so. Sam summed this up by saying, "I'm very persistent, I very rarely get beaten." Four participants also described themselves as having particular qualities that they felt set them apart from their off-line peers (people of a similar age) such as, a 'love of technology' and an 'inquisitive' or 'enquiring' nature. Whether particular personality traits are linked to uptake of online social networking by older adults may be an area for future research.

All five participants indicated a strong belief in sharing information and supporting others in their computer use where possible, and had integrated internet use into their lifestyle as a valuable tool. The findings of this study suggest that the use of the internet is associated with modern life, as participants claimed they would 'be lost without it' which is consistent with earlier research by White and Weatherall (2000). It was also evident that four of the participants felt their off-line peers were missing out on a 
valuable resource and such peers were described as 'mad' or 'lazy' because they were not engaging with the internet.

\section{Internet and social connectedness}

All participants indicated that they used the internet for a variety of purposes which were experienced as supportive to social inclusion and connectedness. One such purpose discussed by all participants was the timely sharing of photographs online. Participants reported that this enhanced feelings of participation and connection with friends or family when it was not possible to be physically present. Receiving photos in a timely manner also appeared to promote feelings of being included in events. For example, Andy was unable to attend a family birthday party and describes what it meant to receive photos the same day, "so that night he sends me the photographs of the party. And it's just wonderful you know..." One participant described a family member's new haircut with excitement because as he/she had felt included in a timely manner, "I got a wonderful photo this morning, first thing" (Sam). This example highlights how the timely sharing of photos has a significant impact on some people's sense of social connectedness.

\section{Social connectedness across the world: The (mis)use of Facebook}

All five participants had sampled Facebook (FB). Four of them initially joined due to the encouragement of family members. However, with the exception of one, all had stopped logging on after a short period of time. There were multiple reasons for the unpopularity of FB. For instance, Sam was concerned about the language used by younger members of the family and found it "offensive and disappointing":

"I was horrified [by the language], but as I say maybe that's age related, I still have standards [I thought] I'm going to get upset over this and I don't need it ... I can't do anything about it" (Sam).

Three of the participants felt that the word 'friend' was misappropriated by FB, as they felt that strangers could not be considered friends. Andy sums up these feelings well: 
"The word 'friend' has meaning to me, it was crazy all these people that want to be my friend that I have never heard of, maybe it's my age but I could see absolutely no sense in it" (Andy).

Of the four participants who joined FB due to the encouragement of family members, two later felt they had been 'used' to add to the number of friends on a list. Jerry highlights how some people may value FB friends more than others, "how many friends you have [is considered] a badge of honour when [really] it doesn't mean anything." Jamie had a similar experience:

"I did activate a Facebook thing, but then he [family member] didn't really communicate. I just think he [family member] wanted a list of friends, [other people] just sort of got on and said "hi, how are you goin" and that was it you know [inaudible] I just thought ah, I can't be bothered" (Jamie).

These responses suggest that some older adults expect friendship to proceed in different forms than those in younger generations, and there was a tendency to interpret friendship requests or behaviours on FB in a negative light if they didn't conform to their expectations. This may reflect generational changes in the pace of life and type of connections people have with each other and the purposes of those connections. Tensions invariably exist between the generations in the social realm (Montemayor, 1983), and it is not surprising that they are expressed in online social spaces as well. These differences do have implications for the relevance of networking sites such as Facebook for older adults, however, and suggests that an online social networking site designed by and for older adults might serve their preferences better.

However, not all participants had negative opinions of FB. Jerry joined FB in order to keep in touch and share photos with family members who were travelling overseas and has continued daily access since. She rarely contributes due to lack of knowledge and confidence with the site. However, she enjoys the connection it provides her with family since through FB she developed a closer connection to a distant family member. Jerry explains, "through Facebook I found out it was her birthday, I didn't really know [before I saw it on FB] so I rang her." 
Through collecting photos sent by family members through the internet, one participant had figured out how to create a slideshow on their computer which they enjoyed immensely:

"[It is] a delight to have them [photos] on the computer, because from not looking at them for one year's end to the other we now often see them [as a slideshow] when the computer is supposed to be idle [laughs] which is a bit naughty, but it's good to see all these" (Sam).

\section{Social connectedness vs. productive use of time}

The notion of 'naughtiness' or indulgence associated with enjoyment of social networking via the internet was a common theme amongst participants, and it became apparent that participant's values shaped the way they used time. For instance, all participants discussed the acceptability of online activities in relation to how productive they were found to be. All five participants were retired from the paid workforce for several years. Several of the participants felt that although playing online games was enjoyable, it was not a worthwhile activity. Self-discipline was used to limit the time spent playing games. In the following extract, Andy, who suffers chronic pain that is worse at night, discusses his ambivalence about playing an internet game he enjoys. Andy reports that even though playing the game takes his mind off his constant pain, he thinks it is not the right thing to do:

"There's nothing or no one who says that I cannot go on and play [a game] till four o'clock in the morning if I want to. Just me, just me and it wouldn't really make any difference to what I was like the next day because I'm not sleeping if I'm in bed. You know, most of the time I'm not [sleeping] It is pain that keeps me awake [and], even though you are playing [a game] you've still got pain [but it's] not quite the same. I suppose I should...utilize it [the computer] more but it's just ...your upbringing. You know when things are right and wrong" (Andy).

Four out of the five participants also expressed ambivalence about the 'rightness' of certain activities at certain times of the day and lengths of time. They grappled with 
the need to justify their enjoyment of online social networking on the basis of a long work history and having 'done their bit'. The participants in this study clearly identified keeping busy and using time productively as important to them. However, when participants compared themselves to younger family members, they often considered their time on the internet as having lesser value or importance than the time of the family member as will be discussed in the next section.

\section{Needs insignificant and not a priority now that l'm 'old'}

A common theme identified during analysis was that older people's needs may not be highly prioritised by younger family members as indicated in the following excerpt. "I want to learn more but I can't get these kids [to help], they are all too bloody busy" (Jerry).

Three participants described patiently waiting for technical support from family members for extended periods of time, and felt reluctant to follow up requests for fear of being seen as 'a burden', as expressed by Jerry:

“I don't want to pester them... when I see anybody free [ I ] say, 'do you mind telling me this' and they do, they'll come in and show me, they're great. It's just me asking them. I don't want to over-do it" (Jerry).

While this participant was reluctant to "over-do it" by asking for support he/she also expressed outrage when friends were forced to wait for help with using the internet. This varying level of expectation of support for self and others may point to the strong loyalties and familial bonds participants have for their own families. It could also indicate that the needs of others are seen as more significant than their own, and that 'burdening' their family may risk alienation from those upon whom they depend. This suggests older adults may at times feel vulnerable due to their dependence on others, contributing to power relations which leave them in situations that are not in their best interests. 


\section{Support to optimise social networking potential of the internet}

While power relations will be discussed in more detail later in the paper, the issue of dependence on support in order to participate in online social networking is also in need of attention. Support available to access the internet for online networking varied amongst participants, with family members taking an important role in the provision of support for three of them. In one instance, remote access enabled timely assistance. Another participant initially paid for computer support until her skills increased. The final participant was highly skilled and a member of a personal computing group, which provided support when required. The idea that younger generations are more skilled in computer use was widespread amongst participants.

However, as discussed earlier, for some participants, help was not always available from younger family members in a timely fashion. It is likely therefore that in the current socio-political context, those who benefit most from online networking are those who already enjoy a reasonable level of social inclusion and support, and have the skills or 'social capital' (Bourdieu, 1977, 1991) to set up their own mechanisms to ensure social connectedness. Social capital refers to "various kinds of valued relations with significant others" (Shucksmith, 2000, p. 213). Shucksmith (2000) observes that, in rural communities, those most privileged were able to make the most of opportunities for social connectedness, leaving the most marginalized in a continued isolated position. As seen from the current study, participants who were least supported by their younger family members had fewer opportunities to connect socially online than those who were well supported.

\section{Making do}

Related to this, not surprisingly, the study found that some older people were limited in their access to technology as a result of financial hardship associated with reliance on the age pension. The implications of this are significant, however, in relation to opportunities to engage in online social networking. One participant considered broadband internet an unaffordable luxury, effectively prohibiting full participation in online social networking. Living on an age pension meant having to justify expenditure on anything that was not essential including the internet. Time and money were weighed up against each other: 
“l'd love a laptop but I can't justify ... buying one you know and spending the money on it, this one's fine. It's slow and I'm not on broadband, well I just think I can't justify spending that money, it's not as though I'm in a hurry. I'm on dialup and so of course I have to wait while it, while it comes on, but I'm not going anywhere [laughs]. If you're working fair enough, but when it is purely and simply for pleasure, I don't, I couldn't justify it" (Andy).

The participant quoted above also framed the decision to use dial-up internet rather than broadband, as a choice based on personal work ethic and personal priorities. However, the participant then revealed that managing on the age pension was difficult and financial considerations effectively denied her the ability to make a selective choice.

\section{Familial power relations}

Two of the participants talked about how family members and friends had experienced a lack of access to the internet, and were subject to the will of more powerful others. "She doesn't email but...I mean she's as smart as anything, but she's not allowed to [use the computer]. He's not into sharing" (Sam). Family members with technical skill had the power to limit internet access of those that were dependent on them. This was at times through passive means, such as not providing support when it was needed, as the following quote describes:

"She's bought herself a laptop. She wanted to get onto Skype to talk to her sister [overseas]. The sister has it, it's all there, but the [family member] has not set up the Skype. So they are still texting each other... which is ridiculous" (Jerry).

These findings suggest that although family members play an important supportive role in older people's engagement with online social networking, complex relationships and power dynamics are significant considerations in actual access to it. 


\section{Discussion and recommendations}

The findings suggest that in some instances younger family members provide ongoing, long-term support with internet use for their senior family members, as part of the reciprocity of family relationships. This familial support was greatly appreciated by older adults in this study. However, in some instances, issues of familial power relations further isolated the older adults. Some seniors appear to have internalised beliefs that their needs and time are less important than those of young people, and carry a fear of being a 'burden' on them. This in turn caused them to devalue their goals and limit their behaviour which impacted on their capacity to enjoy social connectedness and inclusion via the internet.

In addition, participants in this study highlighted the importance of the productive use of time and the moral values attached to their use of time. Current political climates which value productivity and self-sufficiency contribute to a community expectation of self-sufficiency in old age, and generate internalised negative attitudes amongst seniors. An awareness of these moral values offers opportunities for those working with the elderly to challenge the under-valuing of social contributions seniors make, such as the sharing of wisdom. A government advertising campaign which recognises the significant contributions of older people in society, would counteract the 'burden' discourse that some older adults appear to have internalized on the basis of no longer being 'productive'.

Further, this study suggests that some seniors have a diminished sense of financial entitlement in regard to access to online social networking, and take pride in 'making do' in the face of economic hardship and uncertainty. Thus, socio economic factors are contributing to the age related digital divide and are causing repercussions for how older Australians experience participation in online society.

Therefore, it is argued if subsidies were provided to meet the costs of purchasing hardware, connecting to broadband and ongoing support is provided, significant barriers would be removed for many older adults. In addition, in order to promote social inclusion of the most isolated, initiatives such as a community internet support network could be established which included a social networking site for seniors to join if they prefer. 


\section{Conclusions and implications}

The participants of this study were found to use the internet to enhance their social connectedness, and had varying levels of desire to participate in, Skype, Facebook, and sharing photos. All participants expressed a strong belief in their own abilities to learn how to use the internet, but three of the participants also expressed a need for support from family members in order to make the most of the social networking potential of the internet. It was evident that internet use had become an integral part of daily life for participants, an invaluable tool that was relied upon.

In some instances, economic hardship limited participation and internalised restraint restricted engagement with online social networking, as did age-related cultural preferences. Family influence was found to be a strong factor to participation online, and this study also uncovered some of the ways in which power dynamics influenced the support and opportunities provided.

The findings and associated recommendations offered should be considered in light of the study's limitations, however, which include the use of convenience sampling, the small sample from a limited age range, gender bias and the lack of cultural and geographic diversity. These factors result in a sample that is not representative of the wider population and findings cannot be generalised (Marlow \& Boone, 2005). In addition, eligibility to participate included having access to a computer, which meant that those who did not have access were excluded. Nevertheless, offering the perspectives of five individuals is valuable as it provides an inside look at how the internet has increased social connectedness for some older adults, but not the ones most in need, such as those with significant financial restraint or those most isolated. The research has highlighted issues that are of importance to the participants and also offers new insights into some possible ways that social connectedness may be promoted through initiatives targeted at those most marginalised. This exploratory study provides a basis for further research. 


\section{References}

Australian Bureau of Statistics [ABS]. (2008). 3222.0 - Population projections, Australia, 2006 to 2101. Retrieved June 15, 2011, from <http://www.abs.gov.au/ausstats/abs@.nsf/Latestproducts/3222.0Media\%20Rele ase $12006 \% 20$ to $\% 202101$ ? opendocument\&tabname $=$ Sum(Jamie)\&prodno=3222 $.0 \&$ issue $=2006 \% 20$ to $\% 202101 \&$ num $=\&$ view $>$

Australian Bureau of Statistics [ABS]. (2006), 4833.0.55.001 - 'Health of Older People in Australia: A Snapshot, 2004-05'. Retrieved September 26, 2011, from http://www.abs.gov.au/ausstats/abs@.nsf/mf/4833.0.55.001/

Australian Institute for Primary Care (2008). The active service model: A conceptual and empirical review of recent Australian and international literature (1996-2007), Melbourne: La Trobe University Faculty of Health Sciences.

Bourdieu, P. (1977). Outline of a theory of practice. Cambridge: Cambridge University Press.

Bourdieu, P. (1991). Language and symbolic power. Cambridge: Harvard University Press.

Blaschke, C. M., Freddolino, P. P., \& Mullen, E. E. (2009). Ageing and technology: A review of the research literature. British Journal of Social Work, 39, 641-656.

Buse, C. E. (2009). When you retire, does everything become leisure? Information and communication technology use and the work/leisure boundary in retirement. News Media \& Society, 11(7), 1143-1161.

Campbell, R. J. (2008). Meeting Seniors' Information Needs: Using Computer Technology. Home Health Care Management \& Practice, 20(4), 328-335.

Charmaz, K. (2006). Constructing grounded theory: A practical guide through qualitative analysis. London: SAGE Publications.

City of Greater Geelong. (2011). Community profile, Lara ABS state suburb, Where were we born. Retrieved October 22, 2011, from $<$ http://profile.id.com.au/Default.aspx?id=268\&pg=103\&gid=240\&type=enum>

Healy, J. (2004). The benefits of an ageing population. Discussion Paper Number 63, March 2004. The Australia Institute.

Hogeboom, D., McDermott, R., Perrin, K., \& Osman, H. (2010). Internet use and social networking among middle aged and older adults. Educational Gerontology, 36, 93-111.

Hughes, M., \& Heycox, K. (2010). Older people, ageing and social work knowledge for practice. Crows Nest: Allen \& Unwin.

Lam, L., \& Lam, M. (2008). The use of information technology and mental health among older care-givers in Australia. Journal of Aging and Mental Health, 13(4), 557562.

Marlow, C. R., \& Boone, S. (2005). Research methods for generalist social work $\left(4^{\text {th }}\right.$ ed.). Belmont: Brooks/Cole-Thomson Learning.

Maidment, J., \& Macfarlane, S. (2009). Debating the capacity of information and communication technologies to promote inclusion. In A. Taket, B. R. Crisp, A. Nevill, G. Lamaro, M. Graham \& S. Barter-Godfrey (Eds.), Theorising Social Exclusion (pp. 95-104). Abingdon: Routledge.

McLennan, W. (1999). Older people, Australia: A social report, Canberra: Australian Bureau of Statistics. 
Montemayor, R. (1983). Parents and adolescents in conflict: All families some of the time and some families most of the time. Journal of Early Adolescence 3(1-2), 83-103.

Mruck, K., \& Mey, G. (2007). Grounded theory and reflexivity. In A. Bryant \& K. Charmaz (Eds.), The SAGE handbook of grounded theory (pp. 515-538). London: Sage.

Mukherjee, D. (2010). An exploratory study of older adult's engagement with virtual volunteerism. Journal of Technology in Human Services, 28, 188-196.

Nevill, A. (2009). Over 60 and beyond ... the alienation of a new generation: Exploring the alienation of older people from society. In A. Taket, B. R. Crisp, A. Nevill, G. Lamaro, M. Graham \& S. Barter-Godfrey (Eds.), Theorising social exclusion (pp. 134-142). Abingdon: Routledge.

Nimrod, G. (2010). Seniors' online communities: A quantitative content analysis. The Gerontologist, 50(3), 382-392.

Phillipson, C. (2007). The 'elected' and the 'excluded': Sociological perspectives on the experience of place and community in old age. Ageing and Society, 27, 321-342.

Selwyn, N. (2004). The information aged: A qualitative study of older adults' use of information and communications technology. Journal of Aging Studies, 18, 369384.

Shucksmith, M. (2000). Endogenous development, social capital and social inclusion: Perspectives from LEADER in the UK. Sociologia Ruralis, 40(2), 208-218.

Westlake, C., Evangelista, L. S., Stromberg, A., Ter-Galstanyan, A., Vazirani, S., \& Dracup, K. (2007). Evaluation of a web-based education and counseling pilot program for older heart failure patients. Progress in Cardiovascular Nursing, Winter, 22, 20-26.

White, J., \& Weatherall, A. (2000). A grounded theory analysis of older adults and information technology. Educational Gerontology, 26, 271-386.

\section{Biographical Notes}

Christina Doyle graduated from Deakin University with Bachelor of Social Work Honours in 2012, and was a recipient of a Deakin University Writing Grant. She is also a recipient of the CRS Australia Award for Excellence. She is currently a social worker with the Australian Department of Human Services.

Sophie Goldingay is a Senior Lecturer and Bachelor of Social Work Honours Coordinator in the School of Health and Social Development, Deakin University. She is a recipient of the 2012 Deakin University Vice-Chancellor's Award for Excellent Contributions to Equity and Access. 